\title{
A Controlled Environment Model for Dealing with Smart Phone Addiction
}

\author{
Irfan Uddin $^{a}$, Adeel Baig ${ }^{b}$, Abid Ali Minhas ${ }^{b}$ \\ ${ }^{a}$ Institute of Computing, Kohat University of Science and Technology, Kohat, Pakistan \\ ${ }^{b}$ College of Engineering, Al Yamamah University, Saudi Arabia
}

\begin{abstract}
Smart phones are commonly used in most parts of the world and it is difficult to find a society that is not affected by the smart phone culture. But the usage of smart phone is crossing the limit of being used as a facility towards high level of abnormal dependency on the phone. This dependency can reach to the point where we have no longer control on the over-use and hence the negative impacts it can cause to our lives. The worst situation is that people do not even consider that this dependency is actually a type of addiction and we need to find some solutions to deal with it. In this research paper, we identify symptoms that show the existence of smart phone addiction and demonstrate that this addiction has an effect on the quality and even quantity of people' lives and it can ultimately affect the whole society. We propose solutions to deal with smart phone addiction and propose the design of a smart phone application to reduce the level of abnormal dependency on smart phones.
\end{abstract}

Keywords-Smart phone addiction; Abnormal use of smart phone; Healthy society; Dealing with smart phone addiction

\section{INTRODUCTION}

Smart phones have become one of the most omnipresent communication devices within the last decade. These devices allow people to connect "any-time", "anywhere" and with "anybody", with the added benefit of mobility and portability. A smart phone operates not only as a mobile phone but as a computer, $\mathrm{mp} 3$ player, video player, internet browser, book reader, gaming device, entertaining device, etc. [1], [2]. People are rapidly adapting smart phones which can be attributed to many factors such as portability, declining costs, everything at one place and rich features. It is not possible to find a society that is exempted from smart phone culture. With the advancement of technology, smart phones are becoming smarter every generations. In a short time span we find many new applications and features added to smart phones that allow us to perform different functions suitable to our lifestyle [3]. For example, the development of Siri in Apple's phones have allowed people to perform different tasks by just talking to the phone. Thumb impression features have allowed to add security in different operations. Payments through NFC have reduced the dependency on credit cards, and many other features. We do not know what features we will have in smart phones after four or five years.

Smart phones are rapidly adapted, but do they have any negative social impacts? For example, the most common negative consequences of smart phone use include the dangers of driving while using smart phone. This overuse can be termed as smart phone addiction and it can cause detrimental damage both to individuals and to society [1]. Addicted people have a physical or psychological dependence on an entity which disable their functionality within society. Smart phone addicted people have a high dependence on theirs phone and may not able to perform simple tasks without using their smart phone. This situation can be termed as smart phones but dumb people. The study of dependence on smart phones to an extent that the individual's social life is effected has gained little academic attention. The dependency on the smart phones is so much integrated in our lives that people do not even recognize that they are addicted to an entity and they need to find some remedies.

Smart phones are extraordinary devices. We can communicate with each other without time and space restrictions. However, people feel that they can not live a normal life without it [2]. Therefore, the main objective of this paper is to provide some means of making an empirical distinction between normal and problematic smart phone use. This study states that if problematic smart phone use exists, and what activities lead to the abnormal dependency on smart phones. We attempt to identify how the problematic use of smart phone has an effect on the quality or even quantity of our lives. We propose solutions to deal with the problematic use of smart phones through environmental or behavioral programming. We want to defend ourselves against smart phone addiction by using smart phones. Therefore, we propose a model that can automatically determine the abnormal usage pattern of the smart phone and enable or disable different features to get the user out of the danger zone of smart phone addiction.

The rest of the paper is organized as follows. In section II we give definition of addiction and the symptoms of smart phone addiction. We demonstrate how this addiction can affect the quality and/or quantity of ours lives in section III. We present related works in section IV and present a case study that demonstrates the dependency on smart phones in section V. We identify activities on the smart phones that can possibly lead to addiction and present some solutions that advices the user to deal with the addiction in section VI. We present the proposed model which can automatically detect the abnormal behavior of the user on the smart phone and enable or disable different notifications, messages, email or other applications in section VII and conclude the paper in section VIII.

\section{The Signs of Smart Phone Addiction}

An Addiction can generally be defined as the repeated use of a substance despite the negative consequences suffered by the addictive individual [4]. Traditionally addiction has been related to only substance addiction [5]. Examples of substance addiction include smoking, drugs, medication, alcohol 
etc. More recently addiction has been expanded to include behavioral addiction [6]. This type of addiction is defined as the repetition of a particular behavior despite the negative consequences suffered by the addictive individual. Examples include gambling, excessive eating, exercise, internet or cell phone usage etc. More generally we can state that any entity that can produce a pleasurable sensation can be addictive [7]. Cell phones usage can potentially become addictive [8]. With the advancement of technology, all cell phones are becoming smart phones and it is becoming rare to find a portable phone that is not smart phone. In this paper we particularly discuss the addiction of smart phones (not traditional cell phones).

We have lost control over the habitual smart phone use. For example, when we are bored, the first thing we reach is generally our smart phone. Or we have heard many stories of driving while using smart phone that resulted into injuries or possibly the loss of lives [9], but we continue to use smart phones while driving. Or we have heard stories of employees losing their jobs because of using smart phone excessively at work [10] but we continue to use smart phone at work. Or students receive many warnings and possibly reduced GPA because of using smart phone during lecture time, but they cannot stop [11]. This loss of control is a sure sign that we are addicted to smart phones [12]. We are repeatedly using smart phones despite the negative consequences. In this section we briefly explain six signs of smart phone addiction (originally presented in [7]).

1) Salience: The integration of smart phone in the daily routine of an individual is termed as salience. For example, people can be involved in using smart phone while watching movies, religious activities or intimate moments. One might involve in taking selfies at different awkward situations like funerals or changing rooms. People might sleep with their smart phone next to their bed. Many people confess that the last thing they see when they go to bed and the first thing they see when waking up from sleep is their smart phone. We have seen people taking selfies when they perform Umra or Hajj (Muslim religious activities). Not only they are taking selfies but they are constantly sharing them on the social media and while performing their Umra or Hajj they keep checking the number of responses on the social media. We have made a transition from the simple capturing of photos to sharing with people.

2) Euphoria: The use of smart phone is often followed or preceded by the excitement or anticipation. This feeling is called Euphoria or mood modification. We do not know what we can possibly have behind the whistle or beep of the smart phone, and feel really excited to check it immediately. For example, when we are bored we reach our smart phone in order to play games or go to online social networking. We use smart phone in order to avoid awkward situations e.g. pretend to take calls. All these activities take us from one form of mood to another form of mood where we feel excited.

3) Tolerance: The behavior is repeated with everincreasing need. Research has found that the longer someone has had their smart phone the more they are likely to use it [7]. It is not the case that you own the smart phone and then after some time you get bored from it as it is normally the case with other things like a house, furniture, car etc. The desire of using the smart phone again and again increases.
4) Withdrawal: When we are separated from our smart phone we feel anxious or depressed or even get panic. People have found that they feel isolated or lonely when they are away from theirs phones. People have an irrational fear of losing their phone. A simple question to check the withdrawal symptom can be how long does it take to replace when your smart phone is broken, lost or stolen? The sure answer for many is "not very long".

5) Conflict: When we are addicted to smart phone then the common outcome is conflict with other people. For example, parents have arguments with their children because they do not listen to them. Children complain about their parents of not getting enough attention. Teachers are in conflict with their students, or employers are in conflict with their employee.

6) Relapse: When we realize that using the smart phone has an effect on the quality of our lives but when we try to attempt to stop the usage, we cannot stop it. It is like a bad habit say smoking, we try to stop it but then we relapse after a short time. The same is true for smart phone usage. You try to keep your self away for some short period of time, but then you get a relapse and use the phone for even longer time.

\section{The EFFECT of SMART Phone Addiction ON THE QUALITY AND/OR QUANTITY OF LIVES}

One is not addicted to a smart phone the moment he gets a smart phone. But it starts slowly and gradually. For example, at the first place, we own a smart phone mainly for safety reasons. Then we are involved in sending and receiving text messages and then start online social networking. This continues to use smart phone in an extremely dangerous activity like texting while driving. Ultimately we reach to a point where we have no control on the negative consequences from over-using the smart phone. Because of this dependency, the quality or even quantity of our lives are compromised.

The same neural circuitry experienced with substance addiction is activated with smart phone addiction [7]. Early detection of any substance or behavioral addiction is essential for easy treatment. Because when one addiction exists the likelihood of another addiction hiding in the shadows increases [7]. It means that when a smart phone addiction exists then the chances of getting addicted to another behavior or substance increases. Similarly, in addition of treating an addiction others addictions may pop up to take its place [7]. For example, we might treat smart phone addiction but in order to fill the place of addiction in our brain we might become addicted to another entity or activity.

\section{A. Quality of life}

1) Relationship dissatisfaction: Phubbing refers to ignoring someone or ignored by someone by using a smart phone [7]. We all have been in situations where we are either phubbed by someone, or we have phubbed someone. This phubbing can continue in relationship, where partners can phubb each other. It has been observed that smart phones are the major distraction in relationships, because partners spend more time with their smart phones than they should with each other. This distraction is important to consider because it can affect relationship satisfaction and ultimately satisfaction with our lives [7]. 
2) Parent/Child relationship dissatisfaction: Smart phone addiction can have an affect on the relationship between parents and children. If parents are addicted to smart phones, then they may not pay enough attention to their growing children and hence the quality of life of the children are compromised [7]. On the other hand, if adults are addicted to smart phone then it is possible that they start ignoring their older parents who might need more attention. Hence the quality of lives of the parents are compromised.

3) Performance: In case college students are addicted to their smart phone then it might have an effect on their performance at school which can result into lower GPA or possibly dropping from school [1]. Generally, adolescents with poor academic achievements usually receive less respect from surrounding people. Similarly, in case of employees addicted to their smart phones then it is possible that they lose promotion and even get fired from work because their performance is not to the level required by his/her employers.

4) Multitasking: Multitasking (i.e. performing multiple tasks at the same time) reduces efficiency and performance because the brain can only focus on one thing at a time. When we try to perform multiple activities at the same time, our brain lacks the capacity to perform multiple tasks successfully. Roughly 68 percent of the population has an IQ between 85 and 115. Because of the smart phones, people are multitasking, but this multitasking (in reality task switching [7]) has an affect on the IQ by 10 to 15 points, a worse effect than smoking marijuana or losing a night's sleep. It has been found that only 2 percent people can multitask effectively, for the rest of 98 percent multitasking can do more harm than good.

5) Limited attention span: The amount of concentrated time one can spend on task without becoming distracted is called the attention span. In 2000 it was measured that the average attention span of human is 12 seconds. In 2013 by Microsoft it was measured that the attention span of human is reduced to 8 seconds which is one second less than the attention span of a goldfish. This reduction is very much attributed to the development of smart phones and social media. Because, the moment we start to focus on something we receive an email or a notification and our attention is diverted to deal with that notification. We are getting less focused.

\section{B. Quantity of life}

1) Accidents: It is becoming common that people are using their smart phones while driving. Despite many warnings and strict driving policies by the government in many countries it is difficult to control the use of smart phones while driving [13]. This distraction during driving can be dangerous because the driver can get into accident and put his life or other people' lives in danger [14]. This way the quantity of our lives are compromised.

2) Apathetic bystanders: A Bystander effect or apathetic bystander is a social psychological phenomenon that refers to cases in which individuals do not offer any means of help to a victim when other people are present [15]. In these situations the probability of help is inversely related to the number of bystanders. Because people think that someone else can better help the victim or his help will not affect anything. With the smart phone use, we are becoming apathetic bystanders, because when we use our smart phone we are glued to it in such a way that we do not notice what is happening in our surroundings. The worse case is that when we have our smart phone and some body needs our help, instead of offering our help we try to take pictures or selfies with the situation. A famous sociologist Erving Goffman likens technology users as mental patients who treat others as if they do not exist [16].

One such incident happened in September 2013 in a metro station in San Francisco state. One day, people at the metro station were waiting for metro but they were glued to their smart phones. The CCTV camera was recording the whole situation. A murderer came to the station and he had a pistol in his hand. He waved his hand and he even pointed to some people standing there and glued to their phones, but nobody even noticed. He then randomly chose a guy named Justin Valdez ${ }^{1}, 20$ years old, and shot him. This is an extreme example of apathetic bystanders, because those people standing there could have taken some actions to save the victim, but because they were glued to their phones nobody even noticed the murderer until the guy was shot dead. Using smart phones, we are turning to apathetic bystanders and it can possibly affect the quantity of our lives.

\section{RELATED WORK}

Technology addiction has been discussed in the literature for a long time. First paper on Internet addiction was published in 1998 [17]. Mobile devices, being the fastest growing digital devices among other digital products/services across the world, have become a primary driver of internet use today. This section presents recent studies conducted in the field of smart phone addiction.

Authors in [18] investigate the adoption of low cost smart phone and its influence on the students in a selected university in Nigeria. The study shows that mobile phones led to increase in negative social behavior among the young adolescents. In some cases, smart phone helped students to improve their academic performance as well. A study in [19] presents the smart phone addiction in Omani university students. According to the study, Oman has nearly $100 \%$ mobile phone penetration. The study shows that trend of students is towards buying smart phones and they feel uncomfortable without their smart phones. Another interesting study [20] explores the frequency and indices of smart phone addiction in a group of Saudi University students. Indices selected were overuse of smart phone, the technological dimension, the psychological-social dimension, preoccupation with smart phones, and the health dimension The results show that the addiction percentage among the participants was $48 \%$.

Authors in [21] have analyzed the relationship between university students perceived life stress and smart phone addiction. Study concludes that academic stress had negative impact on social and learning self-efficacies, which as a result increase smart phone addiction. Study also reveals that the family and emotional stresses also contribute to smart phone addiction. A study in [22] presents the smart phone usage by Mauritians. Study shows the user trends in using different smart phone services and applications. This trend helps mobile operators

\footnotetext{
${ }^{1}$ http://www.seattletimes.com/opinion/death-of-justin-valdez-a-disconnectcaused-by-technology/
} 
and other businesses in developing and providing value-added services to the Mauritians users. Another paper [23] examines the educational and social uses of smart phone by students in South Africa. The study provides insight into the usage of mobile telecommunication services for different academic and social activities from students' perceptions. The study suggests that the integration of mobile telecommunications into teaching and learning in universities will facilitate studentcentered learning.

A study [24] investigates smart phone usage patterns among students in Serbia. The research aims to provide an insight into the purposes and time distribution of the students' use of their mobile devices. By summarizing the answers given by the participants, authors conclude that $35 \%$ of the students come in the category of smartphone addicts. Authors in [25] investigate how extensive exposure motivates users to use smart phone addictively. Results of an online survey with 384 respondents suggest that there is a strong relationship between convenience, habits and addiction. Convenience facilitates the formation of habit, which generates users' reactions of concentration and enjoyment, which further result in smart phone addiction.

There are different applications developed to deal with Smart phone addiction. These applications include: Breakfree, Moment, AppDetox,Offtime, Flipdapp etc. Breakfree is developed for both iOS and Android platforms, Moment is only available is iOS, AppDetox and Flipdapp are developed only for Android platforms. All these applications blocks certain applications in different duration of time. For example, it might disable Facebook to be used at work time and might disable Outlook during the weekend. We are taking a different approach in the sense that we do not restrict a particular usage pattern on the smart phone until it is leading us to an abnormal usage. For example, a user is allowed to use Facebook during work as long as that usage is not leading towards addiction. We may also be allowed to use work related applications during the weekend if there are requirements and it does not affect the quality of our lives. We analyze the behavior of the user during different times and recommend the usage of the smart phone in such a way that it does not bring any detrimental effects to the society.

\section{Case Study that Shows the Existence of Smart PHONE ADDICTION}

We have conducted a study to measure the existence of smart phone addiction in college students. We asked the students of Al Yamamah University ${ }^{2}$, kingdom of Saudi Arabia to participate in the survey. The number of male and female students participation is given in table II. Most of the participants are college undergraduate students. A total of $73 \%$ are in age range of 18-24 years, while $22 \%$ are in the range of 25-35 years. $70 \%$ of the participants have stated that they have a data plan in their smart phones, and $52 \%$ of the participants have indicated that they spend more than the average expenses on the smart phones (the average expense on phone is 300 SAR in Kingdom of Saudi Arabia). The number of SMSes and calls are shown in table I. As can be seen that $81 \%$ participants made less than 5 SMSes per day and $53 \%$ participants made less than
TABle I. The Male and Female Participation In the Study

\begin{tabular}{lcc}
\hline Sex & No. of respondents & Proportion(\%) \\
\hline Male & 48 & $75 \%$ \\
Female & 16 & $25 \%$ \\
Total & 64 & $100 \%$ \\
\hline
\end{tabular}

TABLE II. FREQUency of SMSES ANd CALls Per Day

\begin{tabular}{lcc}
\hline Frequency & SMSes & Calls \\
\hline Less than 5 & $81 \%$ & $53 \%$ \\
In the range 5-15 & $8 \%$ & $34 \%$ \\
Greater than 5 & $11 \%$ & $13 \%$ \\
\hline
\end{tabular}

5 calls per day. This indicates that the fundamental reason of owning a smart phone for security reasons is vanishing. But as can be observed later that smart phones are used for other activities and most of those activities are possible because of having a data plan in smart phones.

We have asked our participants to indicate the number of hours spent on their smart phone and the response is shown in fig. 1. As can be seen that $65 \%$ of the participants have stated that they spend more than two hours per day on their smart phone. Only $7 \%$ have indicated that they spend less than 30 minutes on their phone. This indicates a high dependency on the usage of the smart phone. We also have collected data to know the type of phone used by the participants. $70 \%$ have indicated that they use Apple's iPhone, 20\% have indicated that they use Samsung and only $9 \%$ participants have indicated that they use other type of phones. This shows that the leader in the smart phone market is Apple. In our survey we have observed that $65 \%$ of the participants change their phone not less than two years.

We have collected the information about the activities performed on smart phones, and it is shown in fig. 2. As can be observed that Youtubing is the most common activity performed on the smart phone. The only activity that is not very popular is movie making. It can also be observed that Send/Receive text activity is shown to be performed very frequently, which is the opposite of the observation that indicated that less than 5 SMSes are sent per day. We think that participants have indicated the send and receive messages through social messages services such as WhatsApp, Line etc.

We have created a questionnaire based on the addiction

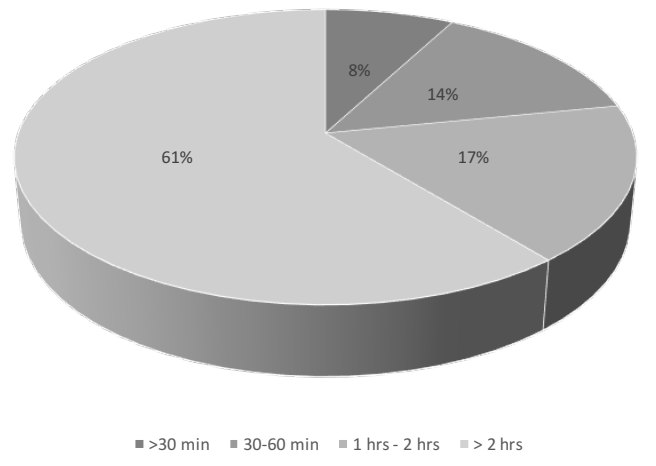

Fig. 1. The amount of time spent on the smart phone per day 


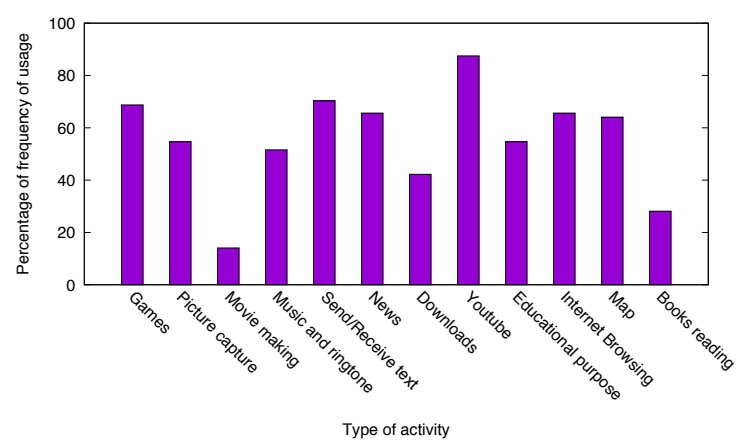

Fig. 2. The frequency of activities performed on smart phone

TABLE III. Questionnaire to Test the AdDiction of SMART PHONE

Salience:

Q1. Is the first thing to reach for after waking in the morning is your smart phone? Q2. Do you sleep with your smart phone next to your bed?

Euphoria:

Q3. Do you use your smart phone when you are bored?

Q4. Have you pretended to take calls to avoid awkward social situations?

Tolerance:

Q5. Do you find yourself spending more and more time on your smart phone?

Q6. Do you think that you spend more time than you should on your smart phone? Withdrawal:

Q7. Do you become irritable when you are away from your smart phone?

Q8. Do you have fear of losing your smart phone?

Conflict:

Q9. Have you been in arguments with friends/family about your smart phone usage?

Q10. Do you use your smart phone while driving?

Relapse:

Q11. Have you tried to reduce time spent on your smart phone but you could not?

Q12. Do you think that you should reduce the time spent on phone but could not?

level measured in [7] and asked the questions given in table III. The scale of measuring smart phone addiction is given in table IV. Those who have answered "Yes" to 2 or less questions are either not interested in technology or have a very high self control. We term them as "scared by technology". Those who have answered "Yes" between 3 to 4 questions are below the dangerous zone called the "tipping point". The "tipping point" is the point where the liking of a smart phone is converted to become a need. Answering "Yes" to 5 to 7 questions means that they have crossed the limit and have already entered the dangerous zone and are moving with full steam towards smart phone addiction. Answering "Yes" to 8 or more questions mean that the individual taking the test has become smart phone addictive.

We have recorded the number of Yes and No answers to each individual question asked in the questioner and is shown in fig. 3. For questions 1 to 8 the percentage of Yes answer is higher than No answers. The higher percentage of No answers for Q9 indicates that they do not get into arguments

TABle IV. The Scale of Measuring Smart Phone Addiction

\begin{tabular}{ll}
\hline Answers & Description \\
\hline 8+ "Yes" answers & $\begin{array}{l}\text { You are addicted to smart phone. } \\
\text { 5-7 "Yes" answers } \\
\text { You have crossed the "tipping point" and are moving } \\
\text { full-steam ahead to smart phone addiction. }\end{array}$ \\
0-2 "Yes" answers & $\begin{array}{l}\text { You have not yet reached your "tipping point" but need } \\
\text { to carefully assess how your smart phone is impacting your life. } \\
\text { You are either living in a monastery or at least have a } \\
\text { very high patience and self-control. Or, technology } \\
\text { simply scares you. }\end{array}$ \\
\hline
\end{tabular}

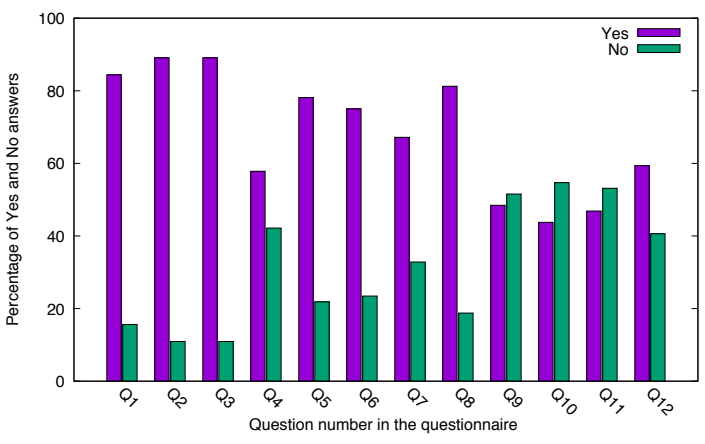

Fig. 3. The percentage of Yes and No answers for all individual questions asked in the survey

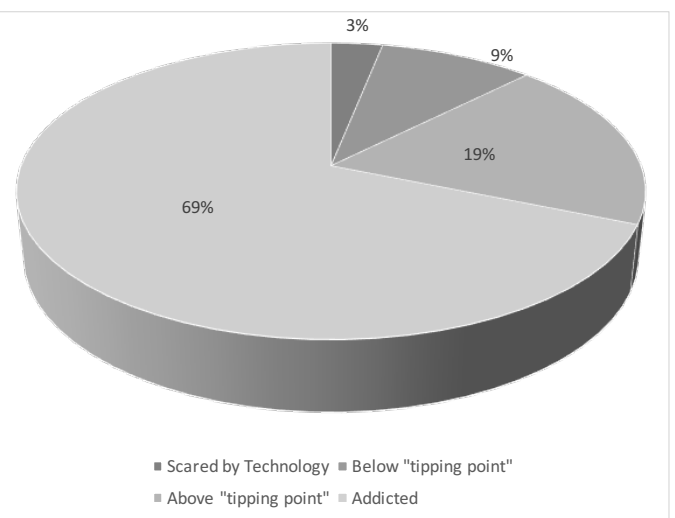

Fig. 4. Smart phone addiction in college students

with friends/family. A possible assumption can be that their friends/family are also addicted to smart phone. The higher percentage of No answers to Q10 is because $50 \%$ of the population are not allowed to drive in Saudi Arabia. The worst situation is that most of the people have not even tried to reduce the over time spent on the smart phone. This can be shown by the higher percentage of No answers for Q11. But the high percentage of Yes answer for Q12 indicates that people think that they should reduce the time spent on their smart phone. This is considered a good sign for improvement.

The result of smart phone addiction based on the scale given in table IV is given in fig. 4. It can be seen that only 9\% students are below the "tipping point". 19\% participants are above the "tipping point" and 69\% participants are actually addicted to smart phones and need a way to deal with this addiction.

\section{ACTIVIties on SMART Phones that CAN LEAD TO AdDiction AND SOLUTIONS TO DEAL WITH IT}

The six signs of addiction given in section II can be observed in different activities that we can perform on smart phones. The reward gained from these activities encourage higher involvement with more and more time spent in the particular behavior. These activities can generally be classified into three categories based on different theories.

1) Escape theory: Those activities that we get involved in order to avoid or get away from an unhappy situation. For example, students use their smart phone in the class because 
they want to escape from listening to a lecture that is not interesting for them. Or in order to avoid a social awkward situation we pretend to talk on our phones. Or in order to avoid social isolation we check some things on our phones. Any activity on the phone that takes us from an unhappy situation to a happy situation can fall in the category of Escape theory.

2) Learning theory: Those activities on the smart phone that help us in increasing our knowledge. For example, accessing social media in order to get knowledge about people/world. Using new apps on the phone to learn something new. Or when we read a text or email we feel that we have completed a task and learned something new. The reward of learning that we gain from different activities lead to addiction.

3) Law of effect: When a behavior is followed by an effective reinforcer the behavior is most likely to happen again. For example, when we pass a waiting time by playing a game on our phone, it is more likely that the next time we are in waiting we are more likely to play the same or similar games again.

\section{A. Dealing with smart phone addiction}

The use of smart phone can be both freeing and slaving. It is liberating in the sense that we are constantly in touch with our friends, family, colleagues or even strangers. We have access to an endless amount of data and continue to live our lives without restrictions of being tied to a particular location. We are master of our domain when we have access to our smart phone, because everything is just a touch away from us. On the other hand, the use of smart phone can be enslaving, because it leads to dependence and more restrictions. For example, having a smart phone, we are reachable 24/7. Our employer can reach us at any time and we are obliged to reply to his/her requests. It might be that at 2:30 AM we feel to reply to an email because it is important. Or the less number of likes to a post on social media can let us feel that no body cares about us.

To quote Richard Branson founder of Virgin Group, ”Do not become a slave to technology - manage your phone do not let it manage you". We need to manage our level of smart phone usage. The good thing is that smart phone are poor masters but very good servants. In order to control our smart phones, we have to exercise some self-control. We must be aware of the usage of our smart phone habits and know what are the activities that we are spending most of the time on smart phone rather than spending in doing a healthy activity. Once we have a list of activities that leads to smart phone addiction we can make plan to cut the amount of time we are spending. For example, instead of spending one hour on social media we can spend some time with friends/family on a cup of coffee. Once we make a plan, we must try to firmly execute it. We can involve friends/spouse to help us executing our plan. For example, they can act as a judge, jury or prosecutor.

We can also program our behavior or environment. A behavioral programming is like self-praising when we achieve to control some time spending on social media. It can be a mental image of getting promotion at work or for students it can be a mental image of getting $\mathrm{A}+$ in a course. We can also offer ourselves a chocolate or a meal out to reward our control. When we fail to achieve a mile stone in dealing with smart phone addiction we can criticize ourselves. We can create a mental image of losing a promotion or failing a course. We can cut the budget or time that we are going to spend on entertainment to criticize ourselves.

Environmental programming is to avoid temptation rather than resist it. For example if we are addicted to shopping the good solution is to avoid going to shopping centers. In case of smart phone addiction, it can be when the phone is in our pocket we are going to check it when it buzzes. A good solution could be to turn off the phone during the activity we do not want to reach to phone. For example, in case of driving instead of putting our phone in pocket, it is better to turn it off and put it in the trunk of the car. This way we will not be tempted to reach to our phone while driving. We can also define smart phone free zones like bed room, dining table etc.

In order to deal with smart phone addiction, we must have to go off the digital grid some times. We are not against technology, we love all the facilities that technology has brought in our lives, but we are saying that the quality or quantity of our lives should not be compromised because of smart phone addiction.

\section{Proposed Model of Application Dealing With SMART PHONE SDDICTION}

The traditional clinical approach for screening and assessment in behavior addictions has been surveys and interviews, and this also applied to smart phone addiction. However, that approach has serious drawbacks and needs to be complemented by objective assessment analysis. First, in interview-based methods, it is difficult to follow the change of subjects status, especially when there is a massively large number of subjects as in smart phone addiction. Second, the survey questions are often subjective and the replies from those surveys depend upon their seriousness, mood, and attitude to the survey. Hence, objective and quantitative usage needs to be recorded to perform diagnosis and treatment based on concrete and accurate data.

We propose the design of an application that observes the behavior of the person and controls the level of addiction. We call the application as Smart Phone Addiction Controlled Environment (Space). The application keeps analyzing all the activities on the phone. There are different software sensors which measures the level of addiction on the smart phone. As soon as an activity is measured to be addictive, the program puts that activity in observation. The program might impose restriction on using the activity or might disable completely until the person is out of the danger zone. The design of Space is shown in fig. 5 .

\section{CONCLUSION}

Smart phones have been deeply penetrated in our lives and we feel that this dependency can reach to a point where a simple benign use of smart phone can have dangerous results. We demonstrated different symptoms of the dependency to demonstrate that smart phone addiction exists and it need to be treated. We cannot afford individuals who put their lives

${ }^{3}$ http://talkmoretechless.com/ 


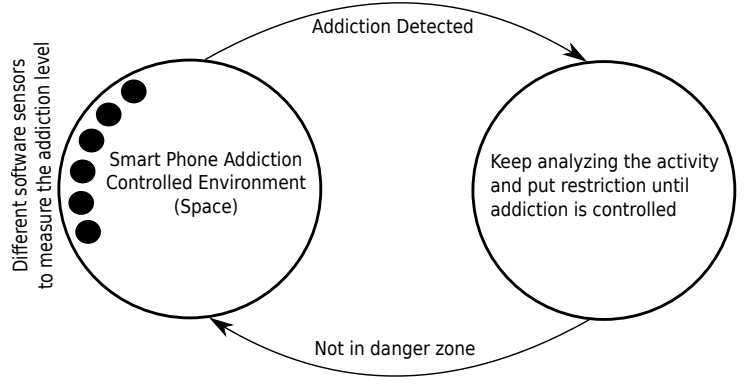

Fig. 5. Smart Phone Addiction Controlled Environment (Space)

or other people' lives at risk. We proposed different ways which help individual to get out of the danger zone of the smart phone addiction. Yet these solutions are very subjective. We think that an objective solution is required to keep people out of the danger zone of smart phone addiction and that is possible only to develop smart phone application to deal with the situation. This way we defend ourselves against the overuse of technology by using the technology. It is worth to mention a community TalkMore TECH LESS which is started for the cause to let people cut the over use of smart phone and connect people with each other.

\section{REFERENCES}

[1] H. Kim, "Exercise rehabilitation for smartphone addiction," Journal of Exercise Rehabilitation, vol. 9, no. 6, pp. 500-505, 12 2013. [Online]. Available: http://www.ncbi.nlm.nih.gov/pmc/articles/PMC3884868/

[2] H. Lee, H. Ahn, S. Choi, and W. Choi, "The sams: Smartphone addiction management system and verification," Journal of Medical Systems, vol. 38, no. 1, 2014. [Online]. Available: http://dx.doi.org/10.1007/s10916-013-0001-1

[3] M. Kwon, D.-J. Kim, H. Cho, and S. Yang, "The smartphone addiction scale: Development and validation of a short version for adolescents," PLOS ONE, vol. 8, no. 12, p. e83558, 2013. [Online]. Available: http://www.ncbi.nlm.nih.gov/pmc/articles/PMC3877074/

[4] T. E. Robinson and K. C. Berridge, "The psychology and neurobiology of addiction: an incentive-sensitization view," Addiction, vol. 95, no. 8s2, pp. 91-117, 2000. [Online]. Available: http://dx.doi.org/10.1046/j.1360-0443.95.8s2.19.x

[5] W. J. Lynch, K. L. Nicholson, M. E. Dance, R. W. Morgan, and P. L. Foley, "Animal models of substance abuse and addiction: Implications for science, animal welfare, and society," Comparative Medicine, vol. 60, no. 3, pp. 177-188, 06 2010. [Online]. Available: http://www.ncbi.nlm.nih.gov/pmc/articles/PMC2890392/

[6] L. Clark and E. H. Limbrick-Oldfield, "Disordered gambling: a behavioral addiction," Current Opinion in Neurobiology, vol. 23 no. 4, pp. 655 - 659, 2013, 23/4 Addiction. [Online]. Available: http://www.sciencedirect.com/science/article/pii/S0959438813000202

[7] J. Roberts, Too Much of a Good Thing: Are You Addiction to Your Smartphone. Santia publishing, 2015.

[8] P. Robert, S. Livia, S. Cisar, R. Andrea, and B. Daniel, "Your constant companion engineering students and their mobile phones," in Intelligent Systems and Informatics (SISY), 2015 IEEE 13th International Symposium on, Sept 2015, pp. 161-165.

[9] K. E. Beede and S. J. Kass, "Engrossed in conversation: The impact of cell phones on simulated driving performance," Accident Analysis \& Prevention, vol. 38, no. 2, pp. 415 - 421, 2006. [Online]. Available: http://www.sciencedirect.com/science/article/pii/S0001457505001867
[10] W. M. Baker, E. J. Lusk, and K. L. Neuhauser, "On the use of cell phones and other electronic devices in the classroom: Evidence from a survey of faculty and students," Journal of Education for Business, vol. 87, no. 5, pp. 275-289, 2012. [Online]. Available: http://dx.doi.org/10.1080/08832323.2011.622814

[11] L. Leung, "Linking psychological attributes to addiction and improper use of the mobile phone among adolescents in hong kong," Journal of Children and Media, vol. 2, no. 2, pp. 93-113, 2008. [Online]. Available: http://dx.doi.org/10.1080/17482790802078565

[12] W. Park, "Mobile phone addiction," in Mobile Communications, ser. Computer Supported Cooperative Work. Springer London, 2005, vol. 31, pp. 253-272. [Online]. Available: http://dx.doi.org/10.1007/184628-248-9_17

[13] A. Ferreira, G. Bianchi Piccinini, S. Rôla, and A. Simões, "Gender and age-related differences in the perception of in-vehicle mobile phone usage among portuguese drivers," Intelligent Transport Systems, IET, vol. 7, no. 2, pp. 223-229, June 2013.

[14] G. Porter, "Alleviating the dark side of smart phone use," in 2010 IEEE International Symposium on Technology and Society, June 2010, pp. 435-440.

[15] J. M. D. BIBB LATANÉ, "Bystander "apathy", American Scientist, vol. 57, no. 2, pp. 244-268, 1969. [Online]. Available: http://www.jstor.org/stable/27828530

[16] E. Goffman, Asylums : Essays on the Social Situation of Mental Patients and Other Inmates. Anchor, Nov. 1961. [Online]. Available: http://www.amazon.com/exec/obidos/redirect?tag=citeulike0720\&path=ASIN/0385000162

[17] K. S. Young, Internet addiction: The emergence of a new clinical disorder. CyberPsychology and Behavior, 1998, vol. 1(3), no. 237244.

[18] S. O. Alaba, "An empirical survey of the rate of mobile phone adoption, its influence on social behavior, schooling and academic works of adolescent students in osun state, nigeria," Education and Management Technology (ICEMT), 2010 International Conference on, pp. 630-635, 2010.

[19] R. Belwal and S. Belwal, "Mobile phone usage behavior of university students in oman," New Trends in Information and Service Science, 2009. NISS '09. International Conference on, pp. 954-962, 2009.

[20] S. S. Aljomaa, M. F. Al.Qudah, I. S. Albursan, S. F. Bakhiet, and A. S. Abduljabbar, "Smartphone addiction among university students in the light of some variables," Computers in Human Behavior, vol. 61, pp. 155 - 164, 2016. [Online]. Available: http://www.sciencedirect.com/science/article/pii/S0747563216302126

[21] S.-I. Chiu, "The relationship between life stress and smartphone addiction on taiwanese university student: A mediation model of learning self-efficacy and social self-efficacy," Computers in Human Behavior, vol. 34, pp. 49 - 57, 2014. [Online]. Available: http://www.sciencedirect.com/science/article/pii/S0747563214000296

[22] R. K. Moloo, "Mobile phone usage behaviour in mauritius," 2011 International Conference on Business Computing and Global Informatization, pp. 607-610, 2011.

[23] O. K. Abatan and M. Maharaj, "Analyzing educational and social usage of mobile telecommunications in a south african university," Information Society (i-Society), 2014 International Conference on, pp. 64-69, 2014.

[24] P. Robert, S. Livia, S. M. \&\#x010C;isar, R. Andrea, and B. Daniel, "Your constant companion \&\#x2014; engineering students and their mobile phones," 2015 IEEE 13th International Symposium on Intelligent Systems and Informatics (SISY), pp. 161-165, 2015.

[25] C. Chen, K. Z. K. Zhang, S. J. Zhao, M. K. O. Lee, and T. Cong, "The impact of mere exposure effect on smartphone addiction," 2016 49th Hawaii International Conference on System Sciences (HICSS), pp. 1507-1514, 2016. 